\title{
Nanophase Strengthening of Hexagonal Metal Alloy Crystals
}

\author{
Vladimir G Tkachenko* \\ I.M. Frantsevich Institute for Problems of Materials Science, Ukraine
}

ISSN: 2576-8840

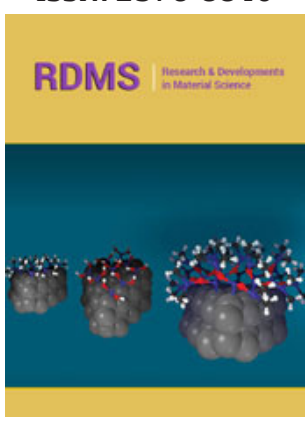

*Corresponding author: Vladimir G Tkachenko, I.M. Frantsevich Institute for Problems of Materials Science, Ukraine

Submission: 觜February 14, 2020

Published: 海 February 28, 2020

Volume 12 - Issue 5

How to cite this article: Vladimir G Tkachenko. Nanophase Strengthening of Hexagonal Metal Alloy Crystals. Res Dev Material Sci. 12(5).RDMS.000800.2020. DOI: 10.31031/RDMS.2020.12.000800

Copyright@ Vladimir G Tkachenko, This article is distributed under the terms of the Creative Commons Attribution 4.0 International License, which permits unrestricted use and redistribution provided that the original author and source are credited.

\begin{abstract}
Selected magnesium and zirconium-based alloys reinforced by nano precipitation hardening and nano dispersion strengthening mechanisms were examined in the power-law regime using long-term testing, strain-rate change measurements and constant structure steady-state creep tests to analyze the deformation and kinetic behavior of hcp Mg-Al-Ca-nm $\mathrm{Al}_{3} \mathrm{Zr}$ and hcp Zr-Sn-Nb-nm $\mathrm{ZrO}_{2}$ alloys at $423 \mathrm{~K}$ and $673 \mathrm{~K}$, respectively. The microstructures generated in these hardened alloys have been assessed by proper techniques aiming at controlling and understanding the composition modification in the nanophasereinforced and nanophase-free hcp magnesium and hcp zirconium alloys. The experimental studies were employed to optimize the composition-processing-microstructure-strength property relationship of the nano-reinforced composite materials in terms of extended uniform strain concept. Under the data of internal friction to be carried out isothermally in the hcp Mg-Ba and hcp Be-Fe, C alloys the deviations from Cottrell-Bilby time law have been revealed due to the non-isothermal kinetics of nanoparticulate nucleation by a pre-precipitate (cluster-forming) mechanism. A series of hcp metal alloys in the Mg-Al$\mathrm{Ca}$ and $\mathrm{Zr}-\mathrm{Nb}$-Sn systems discontinuously nano-reinforced by $\mathrm{Zr}_{3} \mathrm{Al}$ and $\mathrm{ZrO}_{2}$, respectively have been developed as crystalline nanophase materials with more excellent heat and creep resistance as well as higher long-term strength. The observations and findings suggest that the principles of nanophase strengthening should be considered as an effective means of obtaining desirable combinations of mechanical properties due to the nanoparticle-induced delaying of time-dependent shear localization.
\end{abstract}

Keywords: Nanodispersoids; Strengthening mechanisms; Kinetics

Abbreviations: GBs: Grain Boundaries; EPMA: Electron Probe Microanalysis; XRD: X-Ray Diffraction (Analysis); AE: Alloying Element; Q-1: Internal Friction; $\Delta$ : Dislocation Damping; i.e. AmplitudeIndependent Internal Friction; RE: Rare Earth; nm: Nano Meters; SAD: Selected are Diffraction Pattern

\section{Introduction}

Elevated-temperature magnesium, aluminium, titanium, and zirconium-based alloys have received considerable interest with regard to the beneficial properties and major advantages, which are very attractive for wider and more reliable applications of them as structural materials in the industry [1-4]. In recent years, much progress has been made in the alloy development programs which are producing their best-elevated temperature properties $[1,5,6]$ for different dynamic applications in construction modules and high speed rotating systems where excellent creep resistance to time-dependent deformation, long-term strength, high stiffness, low moment of inertia and dimensional stability are essential and still required. Much efforts of international scale are being expended to lower costs in the technologically very demanded aircraft, automobile, and nuclear industries. Traditionally, the strengthened states of high-temperature alloys are achieved by the formation of a structure preventing the motion of dislocations by the precipitation or age-hardening mechanism. With this provision, the strength behavior of them may be essentially improved due to the nucleation and uniform distribution of the desired number of coherent nanoparticles. However, the suitable alloys produced by conventional metallurgy approach cause a series of problems associated with the deterioration of their properties with increasing temperature. To illustrate, harmful precipitate free zones adjacent to the Grain Boundaries (GBs) of polycrystals contribute to the stain localization effects and premature fracture of their inhomogeneous structure. The upper operating temperature of conventional creep-resistant alloys strengthened by known precipitation hardening mechanism is sure to restricted to the limiting temperature above which they no longer exhibit useful long-term strength due to dissolving or coarsening nanoparticles in the matrix. For example, their use for automotive applications is limited by 
the rapid shear failure due to the localization of macroscopic plastic flow and shear band formation. Besides, the obtainable results in the case are often limited by the dissolution capacity of matrices for alloying elements. Furthermore, up to now, it is basically difficult or practically impossible to introduce non-metallic dispersoids in substantial amounts by alloying and heat treatment typical for the above systems. Finally, this is of particular concern for so-called immiscible metal alloy systems.

The development of advanced nanophase materials based on alloys in the metallic systems has become increasingly attractive in recent years. However, the effectiveness of high-temperature strengthening increment by a conventional age-hardening mechanism is lost at temperatures approaching the solvus temperature. Alternatively, the nanophase strengthening has emerged as a means to overcome some shortcomings inherent to the age-hardening technique. Metal matrix nanocomposites is a promising class of structural materials, first of all, for aerospace and automobile industries, and nanophase strengthening is one of the most effective and productive avenues for achieving an optimal combination of properties that could be utilized at much higher temperatures than those presently available by conventional precipitation hardening [7]. Nevertheless, there are many difficult problems that limit the widespread use of many newly developed nano reinforced alloys in industrial applications, in particular, by reason of their low thermal stability, poor creep resistance, weak or inadequate long-term strength. Furthermore, high sensitivity of extremely reactive hcp metal crystals such as magnesium, zirconium, and titanium to oxygen and hydrogen also restrains their use as structural materials. The deficits are being overcome by further alloying and / or process development. A recent approach to alloy design is based on fundamental concepts of their strengthening associated with drag of mobile dislocations by certain components of microstructure solutes, precipitates and dispersoids $[8,9]$. With that, despite research and commercial developments on these systems over the last two decades $[10,11]$ the nanophasestrengthened polycrystalline materials based on them have failed to reach full commercial potential. Unlike thermally activated obstacles such as solute atoms, precipitates, and grain/subgrain boundaries, the nanoparticles as strong a thermal barriers are much more effective for the retention of energetically favorable high-temperature properties of hcp metal crystals to be necessary for the increase in their dislocation long-term strength and stressrupture life. To optimize the nanoparticle-dislocation interaction in a microstructure one should check structural and strain-rate sensitivity of metal crystals in question. In order to overcome this problem, alloy development efforts are focused on the addition of dispersoids to refine the grain size and to minimize strain location. In particular, the attempts have been undertaken to develop the $\mathrm{Al}-\mathrm{Li}-\mathrm{Mg}$ and Al-Cu-Li alloys with fine scale-grained structure and minimal strain localization [12]. In the context, there is a great need for the development of metal alloys having long-term strength at increasingly higher temperatures and stresses. Due to the limited resources in metals and the high demand for new materials with unique properties, the development and use of energy-saving materials such as metal matrix nanocomposites have recently been of great interest to the aerospace and automobile industries all over the world. Dispersion strengthened alloys, especially the oxide dispersion strengthened metal alloys represent an exceptionally promising class of structural materials with a homogeneous distribution of nanoparticles which can provide useful long-term strength theoretically up to operating temperatures approaching the eutectic point of the nanocomposite [7]. The nanocomposites advantages over their conventional counterparts are due to the uniform distribution of thermally stable and non-coursing nanoparticles acting as barriers to dislocation motion in the matrix (crystal lattice).

It, therefore, seems to appropriate to indicate the possibilities for continued work along these lines, since nanophase-reinforced alloys could be utilized at much higher temperatures than those presently available. The main purpose of the on-going study is to explore the potential of the design of the structural alloys with the aim of improving their micro yield/creep resistance and longterm strength below the macroscopic yield stress and of making the best of the potential in obtaining a better combination of properties in selected hcp magnesium and hcp zirconium alloys for different applications. In the context, it is expedient to analyze their composition-processing-microstructure-property relations, in particular, with respect to the impurity interstitials.

\section{Experimental Procedure}

The chemical compositions for alloys in the ternary and quaternary hcp Mg-Al-Ca, X and hcp Zr-Nb-Sn, X systems were selected so as to examine the effects of nanoprecipitationhardening and nano-dispersion strengthening as well as to evaluate their short-term and long-term strength. The choice of the base materials is strongly limited by the favorable compatibility and wetting ability of nano dispersoids such as $\mathrm{nm} \mathrm{Al}_{3} \mathrm{Zr}$ and $\mathrm{nm} \mathrm{ZrO}_{2}$ for hcp magnesium and hcp zirconium matrices, respectively. One of the problems is associated with the difficulty in producing a dispersion of hard, closely spaced and incoherent nanoparticles using normal ingot casting. Chemical compositions were proposed to obtain castable alloys with higher heat-resistance and long-term strength of the alloys under investigation.

It is recently that work has been done to explore and develop new magnesium alloys, primarily because of the well-known engineering problems concerning their melting and suitable fabrication free of contamination. On the basis of previous experience [6,13] with the model magnesium crystals in the $\mathrm{Mg}$-Al system was selected as being the best for our hypothesis testing in terms of kinetic (dislocation) criterion of useful longterm strength [14]. The magnesium alloys nano-reinforced by $\mathrm{Al}_{3} \mathrm{Zr}$ were prepared from high-purity starting materials (with weight content of $99.98 \%$ magnesium and $99.999 \%$ aluminium), processed and produced based on our past experience. The known alloying method was chosen to introduce the nanoparticles into the melt by using an initial pulsed treatment of a melt followed by its rapid solidification (up to $373 \mathrm{~K}$ per sec). A priority method of 
incorporating nanoparticles under the pulse treatment prior to casting makes it possible to expand the solubility limits for so-called immiscible systems with alloying elements having the positive heats of the formation such as e.g., titanium. This is effectively done in the calcium and aluminium containing magnesium alloys additionally strengthened by the stable nanoparticles which have been identified by an electron diffraction technique as being $\mathrm{nm}$ $\mathrm{Mg}_{17} \mathrm{Al}_{6} \mathrm{Ca}_{6}$ phase-natural nanoparticles with an average size of 40 $\mathrm{nm}$ having strong bonding with the crystal lattice.

The maximum strengthening increment from oxides (up to 4 vol. \%) has been obtained in $\mathrm{Ni}$ and $\mathrm{Cu}$-based matrices without unacceptable loss of ductility. One of the oxide species $\mathrm{ZrO}_{2}$ was used in commercially available zirconium alloys. $\mathrm{ZrO}_{2}$ oxide was selected as being a thermally stable and non-coarse compound with the negative free energy of formation. Several refractory zirconium commercially available alloys nano-reinforced with $\mathrm{nm}$ $\mathrm{ZrO}_{2}$ particles were manufactured to analyze the creep resistance of the technical grades in the presence of oxygen. Dispersion strengthening behavior of zirconium-based alloys in the $\mathrm{Zr}-\mathrm{Sn}-\mathrm{Nb}$ system containing strong and infusible nanoparticles of $\mathrm{ZrO}_{2}$ (up to $10 \mathrm{~nm}$ ) as well as incidental impurities of oxygen (up to $0.15 \%$ $\mathrm{O}_{2}$ ) were studied after electro-arc melting in the as-cast condition with strain rate change-related experiments and creep testing at $673 \mathrm{~K}$. The principal nanodispersoids have been identified in as-cast materials by proper electron diffraction technique [15], Electron Probe Microanalysis (EPMA), and XRD analysis as being $\mathrm{nm} \mathrm{Al}_{3} \mathrm{Zr}$ in magnesium alloys and $\mathrm{nm} \mathrm{ZrO}_{2}$ in zirconium alloys under examination.

Analytical XRD method for the mean crystallize size and lattice distortions was also used to calculate the relative values of nanoparticles $[13,16]$. A peak-breath analysis was also performed to estimate the volume-weighted crystallite size and a microstrain averaged all over the coherence length to be perpendicular to the diffracting planes [17]. Tensile creep tests by standard procedure (at constant stress) were commenced after a minimum of $3 \mathrm{~h}$ at the creep-testing temperature to allow for good temperature stabilization. Other details of the testing have been previously reported elsewhere [13]. The Cottrell-Bilby time law testing was performed on selected hcp metal crystals to verify a model for solid solutions with different solutes and excess vacancies by experimental data of dislocation damping (amplitude-independent internal friction), $\Delta$ and mechanical spectrometry, $\mathrm{Q}^{-1}(\mathrm{~T})$. Primary kinetic curves-isotherms of amplitude-independent internal friction $\mathrm{Q}^{-1}(\mathrm{~T})$ were measured for various aging temperatures after solute solution treatment and quenching of specimens prepared from hcp metal crystals.

\section{Experimental Results}

\section{Precipitation-hardening mechanism}

The decomposition of a supersaturated solid solution during subsequent heat treatment leads to the formation of metastable phases or the precipitation of equilibrium phases due to the low diffusion coefficient and the small equilibrium solubility of Alloying Elements (AE). Effective solid solution strengthening requires $\mathrm{AE}$ with a high solid solubility providing a large lattice distortion. The latter limits solubility and restricts solid solution strengthening in most commercial alloys. It is now generally accepted that effective precipitation and dispersion strengthening depend on the size, spacing, fine distribution and degree of coherency of second phase particles which are either looped and bypassed or sheared by mobile dislocations during plastic deformation. The strengthening of metals and alloys is associated with the dragging of mobile dislocations by certain components of structure such as thermally activated obstacles-solutes with weak dragging effect (as small as $0.2 \mathrm{~Gb}^{3}$ ) and athermall strong barriers *) (up to $2.0 \mathrm{~Gb}^{3}$ ).

One should expect good creep resistance even in small-grained polycrystals due to fine particles pinning GBs and impeding dislocation movements [18]. The creep resistance and long-term strength of cast hcp metal crystals can be substantially improved by precipitation hardening but the obtainable results are limited by the temperature dependence of dislocation capacity of their matrices for alloy atoms. Besides, for the alloy systems with limited solubility of their components, quenching from single phase into a two-phase region of equilibrium diagrams results in the formation of metastable precipitates.

\section{Kinetics of age-hardening}

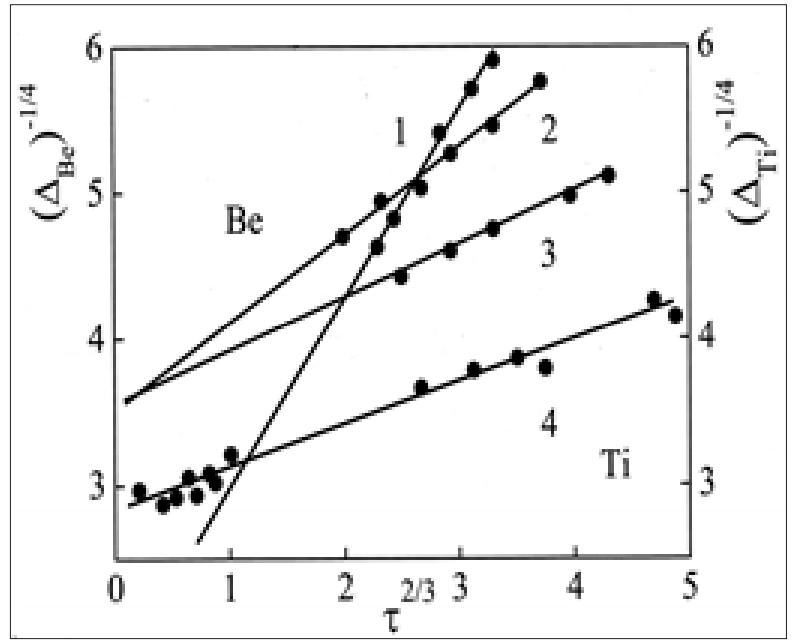

Figure 1: The Cottrell-Bilby time law testing at the most early stage of dislocation damping for hcp Be $(1,2,3)$ and hcp Ti (4) at aging temperatures of 453 (1); 498 (2); 523 (3), and $723 \mathrm{~K}$ (4) under the data of amplitude-independent internal friction.

Isotherms of dislocation damping $\Delta$ in the Cottrell-Bilby coordinates for hcp metal crystals such as unalloyed titanium and beryllium are presented in Figure 1. According to the results obtained the dislocation damping plotted with time obeys a traditional Cottrell-Bilby time law [19], as thermally activated kinetic process

*) G is the shear modulus; $\mathrm{b}$ is the Burgers vector 
with a time exponent of $2 / 3$. The Cottrell-Bilby relation is certain to be valid only for normal solid solutions, e.g. technical grades of hcp metals containing free dislocations that interact with isolated solutes in the early stage of aging. This means that kinetics of dislocation Cottrell locking seems to be occur provided that the isolated inevitable impurity solutes moving to the free dislocations by long-range (diffusion-controlled) mechanism [20]. However, for irregular solid solutions containing excess (strain-produced) vacancies, another mechanism is operating. Indeed, the occurrence of the time and temperature-dependent maximum on the kinetic curves-isotherms for some selected hcp metal alloys cannot be estimated in terms of the Cottrell-Bilby time law and Cottrell locking (Figure 2). Disagreement for hcp solid solutions enriched by excess vacancies with Cottrell-Bilby concept is observed at a later stage of the dislocation damping in a substitutional alloy hcp Mg-Ba, H. Kinetic curves-isotherms are characterized by long-range ordering mechanism with large diffusion length required for migration of solutes towards free dislocations.

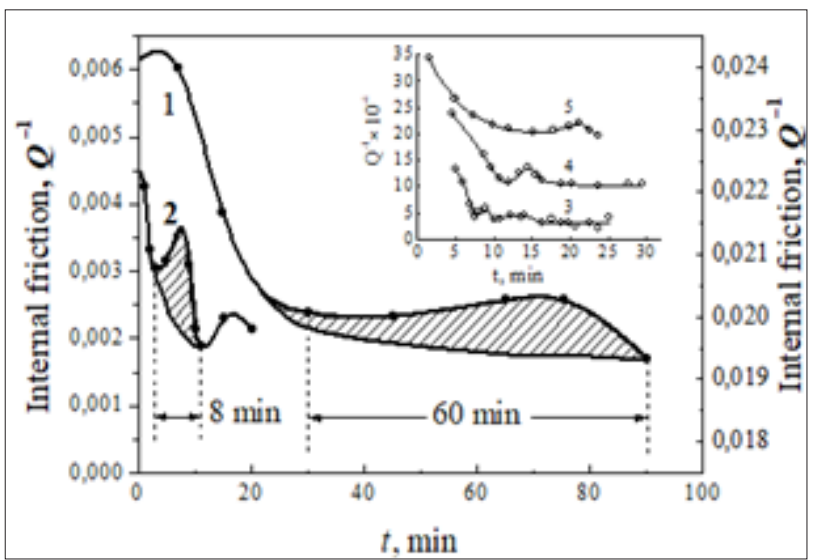

Figure 2: Kinetics of the free dislocation blocking by solute segregations at the most early stages of dislocation damping for hcp solid solutions with activation of short-range (cluster-forming) mechanism at the later stages of aging for Mg-2.1 $\% \mathrm{Ba}\left(\mathrm{Mg}_{0.9} 4 \mathrm{Ba}_{0.06}\right)$ alloy at temperatures of 423 (1) and $763 \mathrm{~K}(2)$; insert: for Be-0.1\% Fe-0.1\% C alloy at aging temperatures of 523 (3), 498 (4), and 453 $\mathrm{K}(5)$.

The kinetics of the irregular damping formation in the interstitial hcp Be-C, Fe, $\mathrm{H}$ solid solutions is similar to that observed in the substitutional hcp Mg-Ba, $\mathrm{H}$ solution after their high-temperature annealing at $923 \mathrm{~K}$ for 10 hours to neutralize influence of the substitutional Fe atoms in hcp Be-C, Fe system. The process is controlled by bulk (long-range) diffusion of the interstitially soluble carbon with the a.e. of about $0.65 \mathrm{eV}$ and its binding energy with dislocations equal to $0.34 \mathrm{eV}$ in the early stage of low-temperature aging in the temperature range of 393-573K (Figure 2). The dislocation damping passes through a temperaturedependent maximum at a later stage of aging which is likely to be due to Be4C cluster formation [21]. It is reasonable to suppose that the origin of these maximums is attributed to the transformation of the pre-cluster separations of vacancy-containing paired defects into the pre-phase cluster compounds (MgmBan and BemCn) by a pre-precipitation (short-range) mechanism with aid of excess vacancies at the later stage of aging. Moreover, it is important to note that in this case the temperature location of the so-called AmBn cluster-induced peak in the discrete temperature spectrum of internal friction $\mathrm{Q}^{-1}(\mathrm{~T})$ does not depend on the frequency of vibrations in the range of $0.5-3.5 \mathrm{~Hz}$. With this provision, the nanophase transformations in the metal alloy systems under investigation are believed to occur finally by a cluster-forming nucleation mechanism.

\section{Nano precipitation hardeninng in Mg-Al-Ca system}

Age hardened alloys suffer problems associated with low ductility; inadequate fracture toughness caused by the sites of preferential strain localization. The effect is due to the precipitation of fine, coherent with the matrix dispersoids in association with the formation of weaker solute-depleted Precipitate Zones (PFZ's) adjacent to the GBs [12].

Unlike the laminated Mg-Al solid solution with divorced eutectics and low creep resistance, the maximum solubility of calcium reduces with increasing the aluminium content of $\mathrm{a}-\mathrm{Mg}$ and decreasing temperature for the equilibrium states of alloys in the Mg-Al-Ca system (Table 1).

Table 1: Maximum calcium solubility in magnesium and hcp Mg-Al alloys.

\begin{tabular}{|c|c|c|}
\hline Alloys System & Temperature, $\mathbf{K}$ & Content by Mass, $\%$ \\
\hline $\mathrm{Mg}$ & 789 & 1.34 \\
\hline \multirow{2}{*}{$\mathrm{Mg}-4.5 \% \mathrm{Al}$} & 793 & 0.5 \\
\cline { 2 - 3 } & 723 & 0.02 \\
\hline $\mathrm{Mg}-8.5 \% \mathrm{Al}$ & 723 & 0.01 \\
\hline $\mathrm{Mg}-12.5 \% \mathrm{Al}$ & 643 & None \\
\hline
\end{tabular}

At higher mass concentration of aluminium (up to 12.5 $\%)$ with the liquidity improved by $30 \%$ the volume fraction of eutectic component $\beta-\mathrm{Mg}_{17} \mathrm{Al}_{12}$ strengthened by calcium increases as much as $15 \%$ with the simultaneous formation of $\mathrm{Mg}_{17} \mathrm{Al}_{6} \mathrm{Ca}_{6}$ nanoparticles on the GBs [6] due to the saturation of a primary $\mathrm{Mg}$-Al solid solution with a fine scale-grained structure. With this provision, calcium impedes the decomposition of a Mg-Al solid solution stabilizing the nanophase composition of $\mathrm{Mg}_{17} \mathrm{Al}_{6} \mathrm{Ca}_{6}$ on the GBs. The interface between the precipitate and the alloy matrix is highly irregular due to the misfit (Figure 3). The surface dislocations surrounding the precipitates, although poorly resolved, are indicative of the partial coherency. With this provision, stable precipitates partially coherent with the disordered matrix are formed due to the dislocation network accommodating the misfit. 


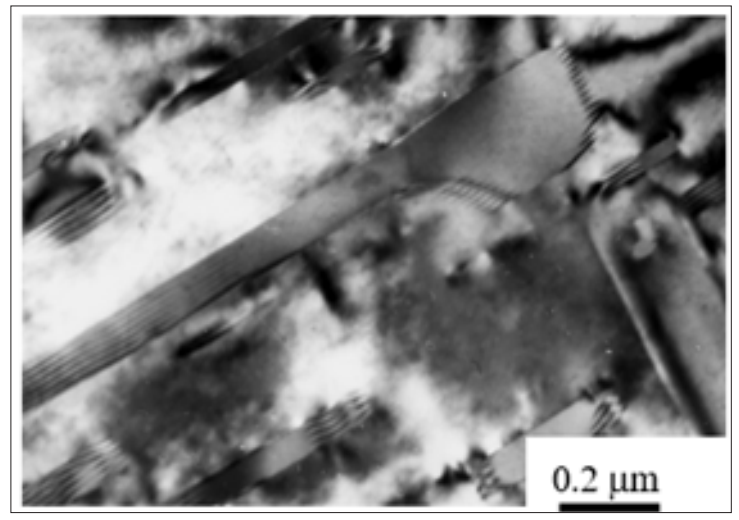

Figure 3: Misfit dislocations at the interface of semi-coherent precipitates after the decomposition of a-Mg solid solution.

Since the hcp magnesium matrix reveals some covalency, coherent (ordered) particles may cause embrittlement by a dislocation cutting mechanism due to the inhomogeneous slip and strong dislocation pileups (Figure 4). Replacement of the coherent interface of the metastable (ordered) phase by a partially coherent interface of the stable $\mathrm{nm} \mathrm{Mg}_{17} \mathrm{Al}_{6} \mathrm{Ca}_{6}$ seems to occur preferentially on GBs. In hypoeutectic systems, the nanophase strengthening of their GBs is most likely to superpose on that contributed by so-called eutectic strengthening which extends the useful longterm strength to higher temperatures. The Table 2 summaries the

The inhibition of dislocation mobility by above-mention mechanisms as well as their forced resistance provide very slow microyielding (at rates of about $10^{-9} \mathrm{~s}^{-1}$ ) making it less sensitive for exposure to higher temperatures, offering heat resistance and causing a delayed fracture. These processes postpone the achievement of the critical dislocation density for a new family of best ternary and quaternary combinations of micromechanical properties obtained for magnesium alloys in the Mg-Al-Ca system. A purified commercially available magnesium alloys in the Mg-Al-CaTi system with the extended uniform tensile creep strain retains its high creep resistance (at $\sim 10^{-9} \mathrm{~s}^{-1}$ ) after 200 hours of creep testing with constant applied load 70MPa. These alloys do have potential in terms of achieving properties suitable for automobile alloys and may be successfully adopted to high-and low-pressure die-casting due to their excellent liquidity (by $30 \%$ ), creep resistance and longterm strength.

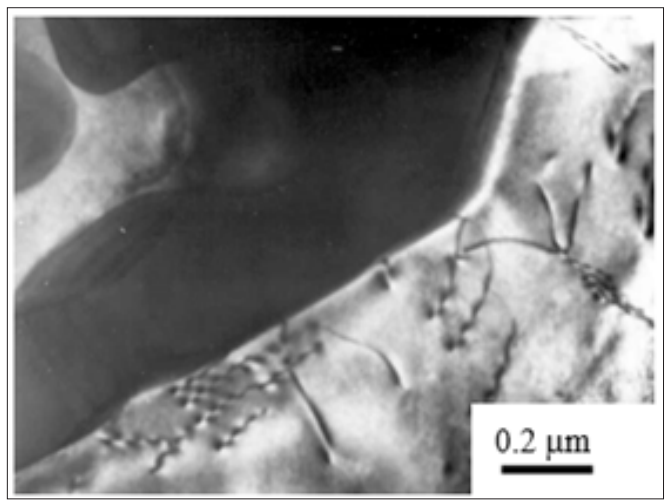

Figure 4: Dislocation pileups at the interface of coherent precipitates after the decomposition of a-Mg solid solution.

the creep-resistant and long-term strength alloys presenting a costefficient system capable to operate with an allowance of total creep strain up to $0.4 \%$ (Table 2). For a given creep strain, long-term strength of the quaternary Mg-Al-Ca, X alloys is compared favorably with AZ91D and ascertained to be 70MPa at $423 \mathrm{~K}$ and 200 hours.

Table 2: Micromechanical properties of conventional and newly developed experimental magnesium alloys with nanoreinforced grain boundaries (GBs) at 423K.

\begin{tabular}{|c|c|c|c|c|c|c|}
\hline \multirow[t]{3}{*}{ Alloy Systems } & \multirow{3}{*}{$\begin{array}{l}\sigma_{\gamma^{\prime}}, \text { MPa at } \\
\text { r.t. }\end{array}$} & \multicolumn{4}{|c|}{ Critical Creep Parameters } & \multirow{3}{*}{$\begin{array}{c}\text { Creep (Strain) Rate } \\
\hat{\varepsilon}_{s^{\prime}}, s^{-1}\end{array}$} \\
\hline & & Creep & \multicolumn{2}{|c|}{ Loading Time, $t^{*}$ hrs } & Allowable Value of Creep & \\
\hline & & & Exp. & $\begin{array}{c}\text { Theory } \\
{[14]}\end{array}$ & & \\
\hline $\begin{array}{l}\text { Mg-9Al-1Zn, AZ91D (Dow Chemical } \\
\text { Corp. USA) }\end{array}$ & 170 & $\begin{array}{l}35 \\
64\end{array}$ & $20050-100$ & 185 & $\begin{array}{l}1.93-2.50 \\
\text { fracture }\end{array}$ & $\geq 10^{-7}$ \\
\hline AZ91D-2Ca & 220 & 64 & 50 & 70 & 0.1 & $10^{-8}$ \\
\hline $\mathrm{Mg}-12.5 \mathrm{Al}-1.3 \mathrm{Ca}$ & 157 & 65 & $160-180$ & 220 & $0.17-0.24$ & $\leq 10^{-8}$ \\
\hline Mg-12.5Al-1.3Ca-0,3Mn- $0.1 \mathrm{Ti}$ & 180 & 70 & $150-200$ & 277 & $0.2-0.4$ & $\leq 10^{-9}$ \\
\hline Mg-12.5Al-1.3Ca-0.4Mn- $0.2 \mathrm{Ti}$ & 210 & 70 & 200 & - & 0.28 & $\leq 10^{-9}$ \\
\hline
\end{tabular}




\section{Mechanism of nanodispersion-strengthening}

In order to overcome a problem of strain localization in solution-hardened alloys, the efforts are focused on the addition of dispersoids to refine the grain size and to minimize strain location. In particular, the attempts have been undertaken to develop the Al-Li-Mn and Al-Cu-Li alloys with fine scale-grained structure and minimal strain localization [22]. Nano reinforced strengthening should consider as a powerful means of aligning the micromechanical properties of structural components all over the bulk of a given alloy. Uniform distribution of the strengthening nanoparticles to much more higher temperature applications and delays a premature fracture of the newly developed metal alloys.
The higher thermal stability of dispersion systems is provided by low-energetic interphasic structures, i.e. low values of the interfacial specific energy, solubility, and diffusivity typical for metallic alloys of eutectic origin [23].

\section{Nanoreinforced magnesium-based alloys}

The practical interest in microstructures of eutectic origin arises from the chemical equilibrium of the two-phase alloys with constituents that are unaffected to chemical decay. Nevertheless, commercially available magnesium alloys such as AZ91D and the like are certain to specified by divorced eutectic and laminated solid solution and as a consequence by low creep strength at higher temperatures.

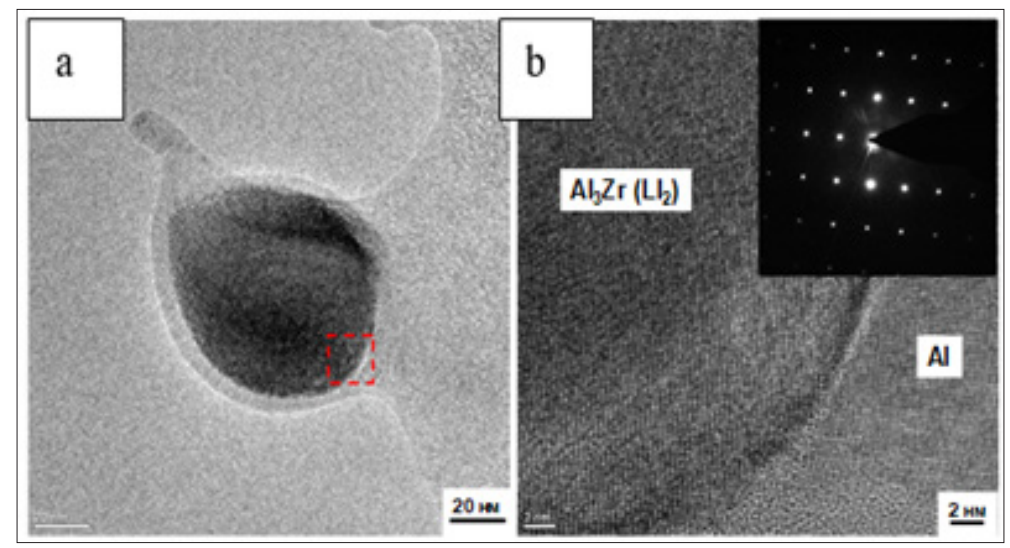

Figure 5a \& 5b: SEM micrograph of $\mathrm{nm}$ intermetallic $\mathrm{Al}_{3} \mathrm{Zr}$ with the effect of strengthening in fcc $\mathrm{Al}$ matrix (a) and a SAD pattern from the $\mathrm{Al}_{3} \mathrm{Zr}$ nanophase with a cubic-type $\mathrm{L} 1_{2}$ lattice that satisfy the criteria of structural isomorphism and the high-resolution image of the selected areas (b).

Microstructural investigations based, in particular, on TEM / SEM technique furnish direct evidence containing the nature of the $\mathrm{Al}_{3} \mathrm{Zr}$ ordered phase, which is precipitated coherently, as may be seen from its spherical shape (Figure 5a). Indexing the Selection Area Diffraction (SAD) pattern (Figure $5 \mathrm{~b}$ ) produces information to identify the $\mathrm{Al}_{3} \mathrm{Zr}$ nano dispersoid. Incorporation of the ordered nanophase into the hexagonal matrix is of great interest due to their wetting ability by a magnesium melt and the use of fcc Al-nm $\mathrm{Al}_{3} \mathrm{Zr}$ compound as alloying composition (ligature) by rapid solidification technique based on a pulsed treatment [6].

Moreover, their phase interfacial bonding is capable effectively of transferring a load from a phase to a phase and to call the effect of natural composite strengthening. Strain rate change creep testing of magnesium alloys in the $\mathrm{Mg}-12.5 \mathrm{Al}$ and nano reinforced $\mathrm{Mg}-12.5 \mathrm{Al}-$ $10 \mathrm{~nm} \mathrm{Al} \mathrm{Zr}_{3}$ systems are presented in Figure 6. Micromechanical properties of purified magnesium alloys under examination can be additionally improved by equalizing the deformation behavior of their structural components on the whole material when incorporating the nanoparticles like $\mathrm{nm} \mathrm{Al}_{3} \mathrm{Zr}$ in the matrix.

To illustrate, the point $\mathrm{A}^{\prime}$ and $\mathrm{A}^{\prime \prime}$ indicate the shift of the ultimate transition from uniform to concentrated plastic deformation with localized shear in the activated sliding region upon introducing the nanoparticles like $\mathrm{nm} \mathrm{Al}_{3} \mathrm{Zr}$ in the crystalline matrix of a $\mathrm{Mg}$ Al primary solid solution. A minute quantity of the useful uniform creep strain is seen to increase by 2 percent for a given nanoreinforced alloy. Nano modificated structure of the magnesium alloy increases creep resistance and strength as well as doubles its lifetime (from 24 to $48 \mathrm{~h}$ ). Furthermore, the strain rate reduces from $7.4 \cdot 10^{-7} \mathrm{~s}^{-1}$ against $2.5 \cdot 10^{-7} \mathrm{~s}^{-1}$ at $100 \mathrm{MPa}$ and $423 \mathrm{~K}$. Thus, the dragging effect in purified magnesium alloys can be enhanced by a nanophase strengthening mechanism provided that the thermally stable nanoparticles pin the GBs. The rare earth (the RE) with atomic numbers from 58 to 71 all have the same chemistry except gadolinium. The main advantage of using the RE alloying elements is that their small amounts to hcp metal alloys produced by ingot metallurgy technique result in a uniform distribution of fine incoherent nanoparticles [1]. However, in magnesium alloys (Table 3), under the data of chemical and XRD analyses, most of the stable RE-bearing nanodispersoids having additions of $\mathrm{Y}$ and Gd pin mainly the GBs, and $\alpha$-Mg matrix is essentially free of the dissolved rare earth. The creep properties of magnesium alloys under investigation at $423 \mathrm{~K}$ and $70 \mathrm{MPa}$ are significantly better than that of the commercial alloys AZ91D, AE42 and AS21. Unlike an AZ series of magnesium alloys with divorced eutectic (AZ91D, etc.) these experimental magnesium-based alloys containing 
cheaper additions compare favorably with higher creep-and heat resistance as well as long-term strength against, e.g. magnesium alloy AE42 (Mg-4 \% Al-2.5 \% RE) containing expensive additions in the temperature and stress ranges of interest for automobile applications.

Table 3: Dislocation creep resistance and long-term strength of several the RE-bearing magnesium alloys.

\begin{tabular}{|c|c|c|c|c|}
\hline Alloy Composition, Wt \% & Creep Strain Rate $\varepsilon_{\mathrm{s}} \mathrm{s}^{-1}$ & Creep Strength, MPa & $\mathbf{t}, \mathbf{h}$ & Required Creep Strain, $\varepsilon$, \% \\
\hline AZ91D (Dow Chemical Corp., USA) & $10^{-7}$ & $\begin{array}{l}35 \\
64\end{array}$ & $\begin{array}{l}200 \\
100^{*}\end{array}$ & $\begin{array}{c}2.5 \\
\text { fracture* }\end{array}$ \\
\hline $\mathrm{Mg}-12.5 \mathrm{Al}-1.3 \mathrm{Ca}$ & $10^{-8}$ & 64 & 200 & 0.35 \\
\hline $\mathrm{Mg}-12.5 \mathrm{Al}-1.4 \mathrm{Ca}-0.3 \mathrm{Y}$ & $10^{-8}$ & 70 & 48 & 0.4 \\
\hline $\mathrm{Mg}-12.5 \mathrm{Al}-1.3 \mathrm{Ca}-0.5 \mathrm{Y}-0.9 \mathrm{Fe}$ & $4 \times 10^{-9}$ & 70 & 200 & 0.24 \\
\hline $\mathrm{Mg}-12.5 \mathrm{Al}-1.3 \mathrm{Ca}-0.3 \mathrm{Y}-0.5 \mathrm{Fe}$ & $1 \times 10^{-9}$ & 70 & & 0.21 \\
\hline Mg-12.5Al-1.3Ca-0.3Y-0.2Gd & $1 \times 10^{-9}$ & 70 & 200 & 0.4 \\
\hline
\end{tabular}

\section{Nanoreinforced zirconium-based alloys}

Nanodispersion strengthening discovers new possibilities for increasing the high-temperature strength of experimental zirconium alloys. In particular, at $673 \mathrm{~K}$ the short-term strength of

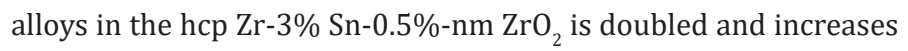
threefold in the hcp $\mathrm{Zr}-1.5 \% \mathrm{Sn}-1 \% \mathrm{Nb}-1.2 \%-\mathrm{nm} \mathrm{ZrO}_{2}$ compared to $\mathrm{Zr}-3 \% \mathrm{Sn}$ alloy (Figure 7). Nevertheless, the steady-state creep behavior of a given zirconium alloy (Figure 8) is similar to that obtained for magnesium alloys (Figure 6) only at higher strain rates when the rapid thermally activated dislocations interact with athermal barriers such as $\mathrm{ZrO}_{2}$ nanoparticles. The curves were directly calculated by interpolating the data obtained from the mechanical tests. The observations were performed in order to describe the strain rate sensitivity of zirconium alloys in the commercially available hcp Zr-Nb-Zn system. Modeling calculations and strength design indicate that the abrupt curves of stress increment $\Delta \sigma$ vs content of nano $\mathrm{ZrO}_{2}$ obtained at higher steadystate creep strain rates gradually change into the smooth curves at lower strain rates. The plot is expected to consist of the two regions separating the entire data into two regions with high and low strain rate sensitivity. A transition to lower strain rates is accompanied by weakening of $\mathrm{ZrO}_{2}$ nanophase strengthening A resulting drag effect on sliding dislocations due to the $\mathrm{ZrO}_{2}$ nanoparticles is active enough only at higher strain rates $\left(10^{-3}-10^{-5} \mathrm{~S}^{-1}\right)$, as can be seen in Figure 8.

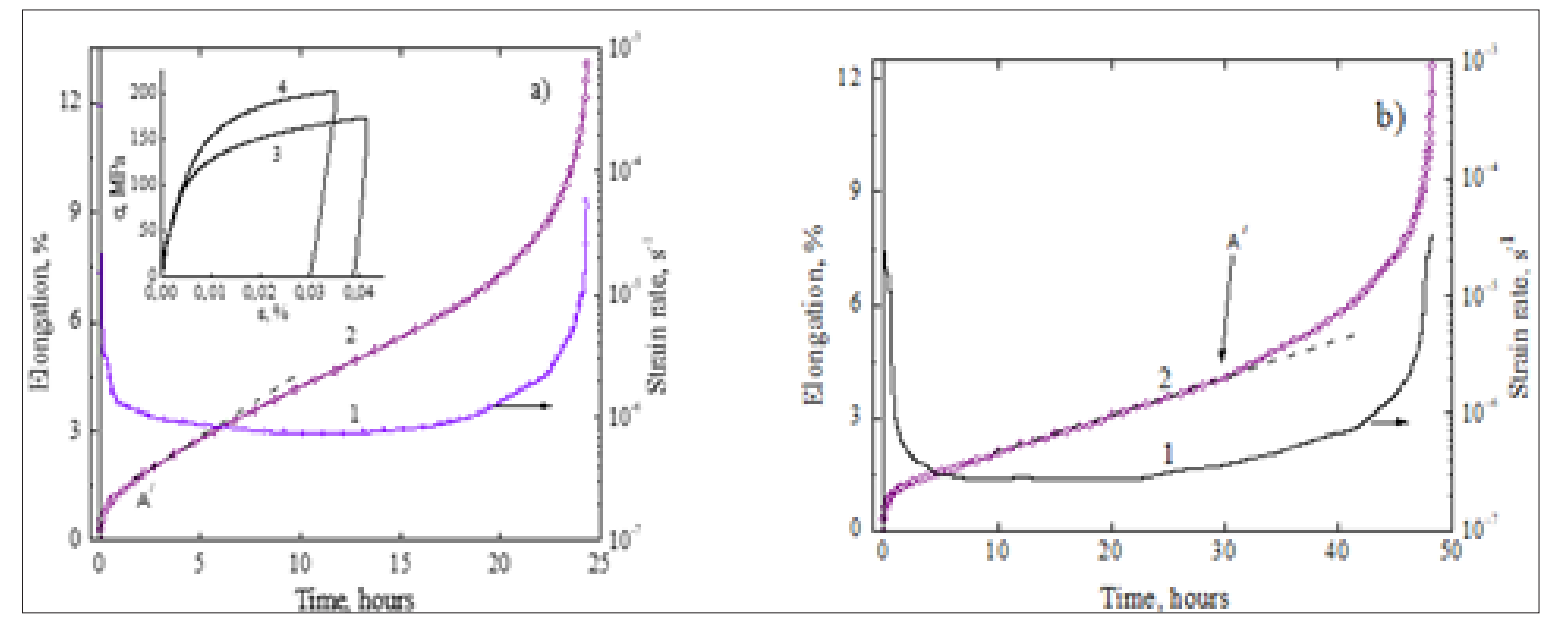

Figure 6a 8 6b: Responses of creep resistance (1) and time-dependent elongation (2) at 100MPa and 423K for magnesium alloys in the hcp Mg-12.5Al (a) and hcp Mg-12.5Al-0.5wt.\% $\mathrm{nm} \mathrm{Al} \mathrm{Zr}_{3}$ (b) systems; insert: typical tensile stress-strain curves for $\mathrm{Mg}-12.5 \mathrm{Al}$ (3) and $\mathrm{Mg}-12.5 \mathrm{Al}-0.3 \mathrm{wt}$ \% $\mathrm{nm} \mathrm{ZrO}$ alloys (4) at 423K. 


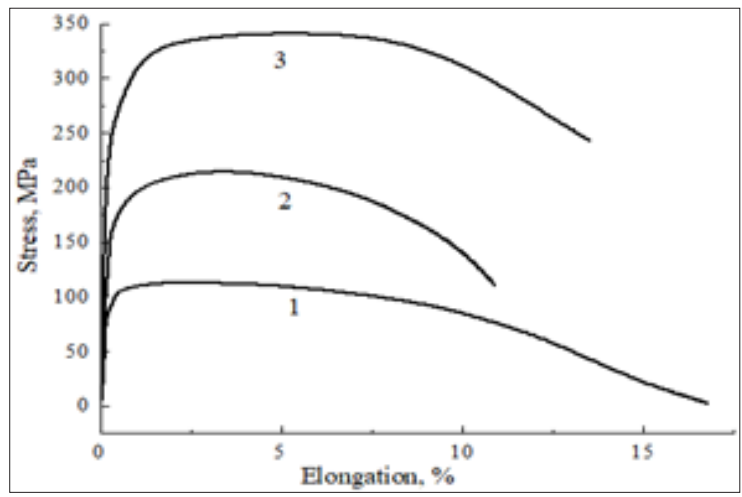

Figure 7: Tensile curves at $673 \mathrm{~K}$ for zirconium- based alloys in the systems hcp Zr-3\% Sn (1), Zr-3\% Sn-0.5\% $\mathrm{nm} \mathrm{ZrO}_{2}(2)$, and $\mathrm{Zr}-1.5 \% \mathrm{Sn}-1 \% \mathrm{Nb}-1.2$ wt. \% $\mathrm{nm} \mathrm{ZrO}_{2}$ (3).

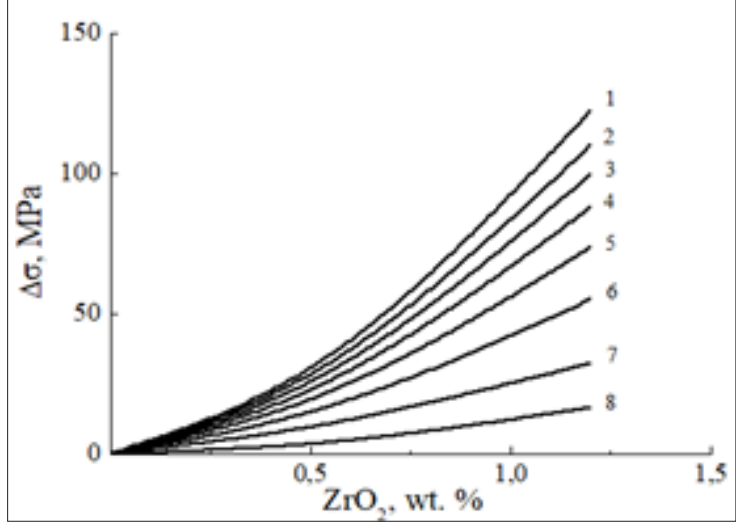

Figure 8: Stress increment as a function of $10 \mathrm{~nm} \mathrm{ZrO}_{2}$ content for $\mathrm{Zr}-1 \mathrm{Nb}-1.5 \mathrm{Sn}-$ nano $\mathrm{ZrO}_{2}$ alloy at $673 \mathrm{~K}$ and different strain rates corresponding curves at $10^{-3}(1), 10^{-4}(2), 10^{-5}(3), 10^{-6}(4), 10^{-7}(5), 10^{-8}(6), 10^{-9}(7)$ and $10^{-10}$ $\mathrm{s}^{-1}(8)$.

It might appear at first glance that the nature of this variation would be rather unexpected. This finding might be well understood if properly provided for a shielding effect [24], of mobile interstitial oxygen that can inhibit the interaction between dislocations, migrating solute atoms and $\mathrm{nm} \mathrm{ZrO}_{2}$ particles upon slowing down strain rate. Quite obvious that the dragging effect depends on the velocity of dislocations to be proportional to the strain rate in the thermally activated region. At higher strain rates the waiting time should be expected to be too short to form the dense Cottrell solute oxygen-containing atmosphere by a long-range diffusioncontrolled mechanism.

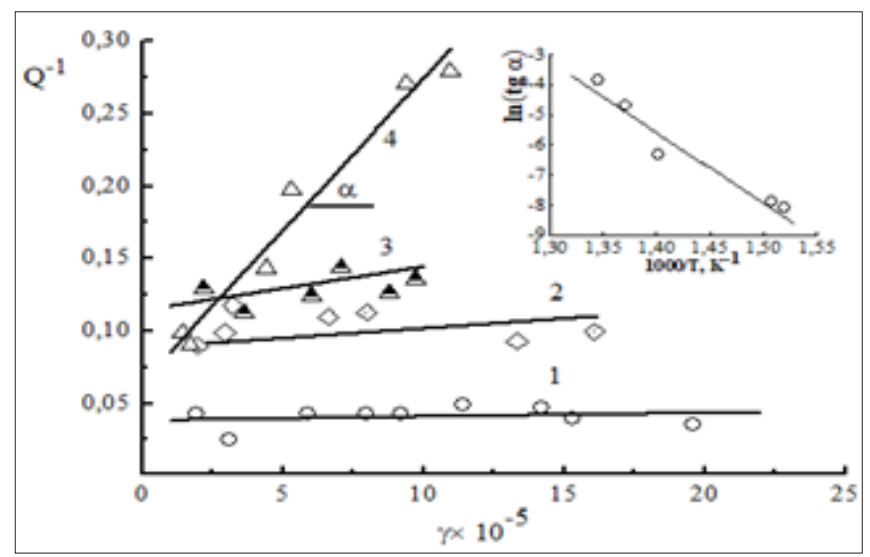

Figure 9: The amplitude dependence of internal friction for hcp $\mathrm{Zr}$ (matrix) containing 0.15 wt. \% $\mathrm{O}_{2}$ with the evaluation in the $\ln$ (tga) -1 / T coordinates the binding energy $\mathrm{E}_{\mathrm{b}}$ between a dislocation and an interstitial solutevacancy paired defect to be of about $2.0 \mathrm{eV}$. 
Itis well-known that zirconium and its alloys are strain extremely sensitive to the presence of oxygen. The impurity interstitial solutes $\left(0.15 \% \mathrm{O}_{2}\right)$ affect essentially on the stain rate and ability to the dislocation dragging effects in substitutional solution-hardened alloys. A striking example of this unusual behavior is given by $\mathrm{Zr}$ $\mathrm{Nb}-\mathrm{Sn}$ and $\mathrm{Zr}-\mathrm{Nb}-\mathrm{Sn}-\mathrm{nm} \mathrm{ZrO}_{2}$ systems in the course of strain-rate change tests. Oxygen is an attendant (technologically inevitable) impurity in technical grades of zirconium with the a.e. for vacancy migration of about $1.6 \mathrm{eV} /$ atom and vacancy concentration on the interfacial surface $\mathrm{ZrO}_{2}-\mathrm{Zr}$ to be $4.2 \times 10^{20}$ vacancies $/ \mathrm{cm}^{3}$ [10]. Under the data of amplitude-dependent internal friction, the observed dislocation damping (Figure 9) is associated with the presence of interstitially soluble oxygen in a parent zirconium matrix which forms the so-called paired defects consisting of an oxygen atom and an excess (strain-produced) vacancy [21]. These defects migrate in the stress field and pin the mobile dislocations by Cottrell locking with the high binding energy $\mathrm{E}_{\mathrm{b}}$ to be $2.0 \mathrm{eV}$ (Figure 9). With this provision, vacancy-type defects are assumed to relax the lattice strain caused by the action of oxygen atoms. The kinetic effect of Cottrell locking is thought to be negligible at high strain rates provided that time taken for the activation process of dislocationinterstitial interaction is too short to allow the formation of dense oxygen-containing Cottrell atmospheres. On the contrary, at slow strain rates, the oxygen atoms give a considerable contribution to the Cottrell atmosphere formation shielding their movement to the athermal barrier $\left(\mathrm{nm} \mathrm{ZrO}_{2}\right)$.

Unusual strain rate response of $\mathrm{nm} \mathrm{ZrO}_{2}$ content is most likely to associate with the competitive interaction of mobile dislocations acting by an interstitial site mechanism with the impurity solutes and by a vacancy mechanism with the substitutional solutes. The slow kinetics of the poor strengthening indicates the preferential segregation of interstitial impurities towards the slow dislocations. The solute atmospheres provide a dragging effect in the stress fields of mobile dislocations when they pass through a lattice and cause the redistribution of solutes and excess vacancies due to their chemical affinity to oxygen. The principal thought is to neutralize the detrimental effect of foreign impurities on creep resistance and long-term strength of hcp metal alloy crystals. Since interstitial impurity atoms such as oxygen and the like impose a strain on solvent lattice restricting dislocation movement in the lattice strain field it is necessary to remove the strain from the total lattice strain by refining or scavenging of interstitial oxygen from primary solid solution using, e.g. erbium, cerium, and yttrium. This approach allows the respective oxides to be formed due to their large negative free energies. With this provision, the main advantages of commercially available zirconium alloys under consideration could be kept at lower creep strain rates.

\section{Discussion}

In age-hardening alloys, there are two types of phase precipitates which can be identified as

A. A metastable (ordered) precipitates coherent with disordered matrix, and
B. Stable precipitates partially coherent with disordered matrix due to misfit dislocations.

Following the Clark concept $[25,26]$ the age-hardening of magnesium alloys in the hcp $\mathrm{Mg}-\mathrm{Al}$ system can be explained by the occurrence of coherent precipitates oriented properly to prevent basal slip as well as by adequate interprecipitate spacing not so small to cause a precipitation hardening effect. However, decomposition of a solid solution is most likely to occur by different mechanisms depending on the degree of oversaturation. The strong oversaturation is specified by the homogeneous distribution of nano precipitates. Alternatively, at weak oversaturation, the preferential nucleation of nano precipitates occurs on the existing dislocations rather than the GBs or interfaces. According to [27] replacement of the coherent interface of the metastable phase by a partially coherent interface of the stable phase is expected to give rise to the change in the mechanism of dislocation-particle interaction. Unfortunately, the operative dislocation cutting mechanism is certain to result in the inhomogeneous slip in the form of strong dislocation pileups. Besides, an observed transition from the cutting mechanism to a bypass mechanism can occur only preferentially on dislocations and GBs with the age-hardening response of the system at higher annealing temperatures. Furthermore, low creep resistance of magnesium is attributed, first of all, by the GBs sliding that might be revealed even at $77 \mathrm{~K}$ as well as by local stresses to be concentrated in triple joints of grains. Since GBs sliding can be the sites of preferential micro deformation and localized shear, hcp metal alloys should have their GBs pinned. The dispersoids lock the GBs making the alloys less sensitive for exposure to elevated temperatures in all the strain rate range [18].

Therate-controlling mechanismsprovide importantinformation for understanding the strengthening as a phenomenon. An original atomistic approach is proposed based on the kinetics of edge dislocation-cluster interactions being simulated at any strain rate within $10^{-7}$ to $10^{7} \mathrm{~s}^{-1}$ for hcp $\mathrm{Zr}$ [28]. Under the data of simulations, the dislocation climb mechanism is expected to operate in terms of the coupled thermal and stress activation effects. Proceeding from this, the coupling of strain rate and thermal activation is considered as a fundamental physical principle of an edge dislocation pinning by clusters of self-interstitial atoms. Atomistic simulations by Yue et al. [28] are consistent with a climbing mechanism modeled by Arzt et al. [29,30].

Following the theoretical concept [29] the dispersoids being introduced through technological cycle (high-speed treatment, precipitation from the liquid, etc.) form with a matrix the incoherent boundaries which attract glide dislocations with increasing temperature. The relaxation of their stress field should be considered as a source of local micro yielding [8] with some density of mobile dislocations which delay the strain localization thermally activated dislocation detachment from the particle is assumed to be the rate-controlling mechanism of dislocation creep. With that, the concept of nanophase strengthening should be experimentally verified in addition. The paired defects 
(associates) are expected to be relatively stable due to the opposite strains and electronic charges imposed by the excess vacancies and addition on the crystal lattice to provide their lowest energy positions within a certain distance from a dislocation in the stress field. The second stage is believed to be the formation of cluster compounds $A_{m} B_{n}$ converted from vacancy-type paired defects. In such a manner, the precipitate nucleation is assumed to occur by a cluster-forming mechanism. Since dislocations are weakly pinned by solute atoms on the based planes [31] the major efforts in the present study were focused on magnesium alloys which are more strong and stable barriers to dislocation movement compared to thermal obstacles. Furthermore, the presence of a high density of the GB nanoparticles is evidenced to be a more stable phase than the matrix strengthening phase [32]. The susceptibility of the polycrystalline materials to shear strain localization can be the main factor that limits their tensile ductility, long-term strength and fatigue resistance $[2,14,33]$. When slip is likely to be relatively easy the plastic deformation is localized and accumulated in soft regions resulting in high-stress concentration, for example, grain boundary triple points. The ductility and toughness deficiencies of a variety of metal alloy systems are caused by strain localization and weakened Precipitate Free Zones (PFZ's) [12]. It is analytically proved [14] that dislocation long-term strength controls the quantity of uniform microyield including creep for slow dislocations which results in the successful advancing of a product. With that, under the data [34] a critical value of dislocation velocity for high-purity crystals is attained at a strain rate of $10^{-8} \mathrm{~S}^{-1}$ and dislocation density $\sim 10^{6} \mathrm{~cm}^{2}$ even at $293 \mathrm{~K}$. These results are in agreement with the values calculated for high-purity magnesium alloy crystals with reference to the criterion of useful long-term strength (Table 2). To attain the lower values of strain rate $\left(10^{-10} \ldots 10^{-12} \mathrm{~s}^{-1}\right)$ it is necessary to extend the range of uniform dislocation strain. Upon treatment developed alloys and useful materials made of them, the new special measures should be taken to prevent a premature localization of shear (timedependent) strain and thereby to improve their creep resistance and long-term strength.

Further essential support for our concept comes from X-ray analysis of the diffraction patterns before and after creep tests of magnesium alloys [13]. The patterns indicate that the constant dislocation density is maintained only as small as $0.4 \% \varepsilon$. At relative strain $\varepsilon>0.5 \%$, the shear localization is certain to occur with increasing dislocation density. This effect is accompanied by the ultimate transition to the plastic instability and necking due to the disintegration of a primary solid solution and local softening its defect structure.

Unlike precipitation hardening, the nanoparticle strengthening of metal matrix composites increases the effectiveness of the uniform strain evolution due to the alignment of slip systems in hcp metal alloys and hence extends the useful long-term to higher temperatures. Since the relaxation of the incoherent particle stress field is a source of local microyielding [8] some density of mobile dislocations should be generated to prevent the undesirable localized shear. Further, one can observe an additional increase in the dislocation creep resistance of a given alloy by a nanophase strengthening mechanism. If nanoparticles decorate the grain boundaries this microstructure proved to be very stable at elevated temperatures. The nanophase strengthening is an avenue for achieving an optimum combination of properties and effective method to prevent early crack nucleation due to strain localization. The approach offers important advantages compared to conventional decisions for strengthening particles being incorporated in the micrometer range. Metal alloy properties can be additionally improved by equalizing the deformation behavior of structural components on the whole material in terms of:

A. Incorporating of the nanoparticles like $\mathrm{nm} \mathrm{Al}_{3} \mathrm{Zr}$ in hcp $\mathrm{Mg}$ and $\mathrm{nm} \mathrm{ZrO}_{2}$ in hcp $\mathrm{Zr}$ provides aligning local creep properties of both structural components for the advanced metal alloy systems due to uniform distribution of the dispersoids and, as consequence, additional dispersion strengthening.

B. Equal-channel angular pressing, i.e. a widely known method of severe plastic deformation in which shear occurs through keeping up the uniform disperse structure using the reusable cycles of the treatment to improve their strength according to the HallPetch relation [35]. Nevertheless, although the strength increases through the dislocation pileups at the GBs by Hall-Petch effect the pinning of GBs by nanoparticles is sure to be more effective due to the stronger interfacial bonding between the nanoparticles and the matrix.

The presence of various kinds of impurity elements cannot be taken into full consideration when constructing the ternary and quaternary equilibrium alloy phase diagram. The sensitivity of extremely reactive matrix materials with hcp structure such as zirconium, titanium, and magnesium to oxygen, nitrogen and hydrogen interstitials produces a problem that has frequently been tackled in alloys prone to impurity interstitial segregations around mobile dislocations. In particular, the rate of solid solution strengthening, e.g. $\alpha-\mathrm{Ti}$ at elevated temperatures is controlled by a mechanism responsible for the thermally activated overcoming of solute interstitials by the first-order prismatic dislocations with the a.e. to be $1.25 \mathrm{eV}$ [36]. Moreover, under the data of amplitude-dependent internal friction in pure hcp Zr containing free dislocations the activation parameters are consistent with those determined for thermally activated deformation mechanism attributed to interstitial solute atoms of oxygen [37]. Following Cottrell-Bilby's concept the solute atoms can diffuse fast enough to allow dynamic interaction with dislocation during deformation, meanwhile, in substitutional alloys, the strain-produced vacancies are likely to enhance the diffusion of substitution solutes. However, a new situation arises in substitutional alloys when the inevitable impurity interstitials form their dense oxygen-containing Cottrell atmospheres which are able to immobilize any sliding system due to a large lattice distortion and to give rise to the strain localization. The detrimental interstitial solute segregations are more likely to lock the sliding dislocations by the Cottrell hardening mechanism. 
Strain-rate sensitivity of pure hcp metal alloy crystals is normally described by the quantitative (dislocation) criterion of useful long-term strength [14]. However, results obtained are in a good agreement with the evaluations to be expected from the postulated mechanism only for nanophase-reinforced magnesium alloy polycrystals of high purity. For commercially available and technical grades of hcp zirconium alloys, larger long-term strength is sure to kept only after interaction with fast dislocations (at strain rates $10^{-3}-10^{-5} \mathrm{~s}^{-1}$ ). Unusual strain rate response to $\mathrm{nm} \mathrm{ZrO}_{2}$ content is associated with the competitive interaction of mobile dislocations with the interstitial impurity solutes by thermally activated interstitial site mechanism and the substitutional solutes by vacancy (diffusion-controlled) mechanism. For cross-slip or dislocation climb mechanism, impurity interstitials such as oxygen are more deleterious than excess (strain-produced) vacancies. The diffusion of interstitials causes the effect of shielding by Cottrell locking mechanism for dislocation-nanoparticle interaction. Unfortunately, thermal stability of dislocation structure in $\alpha-\mathrm{Zr}$ matrix is associated with the formation of oxygen atmosphere having very strong binding energy of about $2 \mathrm{eV}$ due to the effective pinning. For this reason, it is believed that shielding effect [24] resulting from Cottrell-Bilby interstitial solute blocking could be caused by short range ordering of solute interstitials in the stress field of mobile dislocations, as predicted by Snoek-Schoeck dragging concept [34]. The possibility of interference of other mechanism cannot be discarded. At low strain rates the poor correlation between the dragging stress and its strain rate sensitivity is most likely to be associated with the preferential oxygen segregations on slow dislocations by long-range (diffusion) mechanism to lock their sliding towards nano $\mathrm{ZrO}_{2}$ athermal barriers. Therefore, a decrease of the dislocation mobility in alloys with impurity interstitials is controlled by the formation of the dense Cottrell (oxygencontaining) atmospheres, which suppress the interaction of slow dislocations with $\mathrm{ZrO}_{2}$ nanoparticles.

\section{Conclusion}

The following conclusions could be drawn from this study:

A. The kinetics of dislocation damping in the technical grades of hcp metals containing the traces of inevitable residual impurities is well described by a Cottrell-Bilby time law, provided that the isolated solutes move to the free dislocations by the diffusion-controlled long-range mechanism. However, the observed non-isothermal kinetics of dislocation damping in hcp metal alloy systems, e.g. $\mathrm{Mg}-\mathrm{Ba}, \mathrm{H}$ and $\mathrm{Be}-\mathrm{Fe}, \mathrm{C}$ enriched by excess vacancies is associated with the activation of cluster-assisted nanoparticle nucleation mechanism in the later stages of age hardening.

B. A series of nano-reinforced hcp magnesium and hcp zirconium alloys in the Mg-Al-Ca and Zr-Nb-Sn systems, respectively has been developed as nanophase materials with excellent heatresistance and higher long-term strength at elevated temperatures.

C. Magnesium alloys of high purity in the hcp Mg-Al-Ca systems discontinuously nano-reinforced by $\mathrm{nm} \mathrm{Zr}_{3} \mathrm{Al}$ reveal the desirable increase in the dislocation creep resistance and long-term strength over the unreinforced counterparts at $423 \mathrm{~K}$ (up to $70 \mathrm{MPa}$ for 200-hours life).

D. Nano oxide strengthening discovers new possibilities for increasing the high-temperature strength and heat-resistance of hcp zirconium alloy crystals. In particular, at $673 \mathrm{~K}$ short-range strength of zirconium alloys is doubled in the hcp $\mathrm{Zr}-3.0 \% \mathrm{Sn}-$ $0.5 \% \mathrm{~nm} \mathrm{ZrO}_{2}$ system and increases threshold in the hcp Zr-1.5 $\% \mathrm{Sn}-1 \% \mathrm{Nb}-1.2 \% \mathrm{ZrO}_{2}$ system. The promising results indicate that the useful increment of properties is believed to be caused by the preferential nanophase-pinning of grain boundaries. With the impeding of dislocation mechanisms, the systems can be expected to give a sounder result.

E. The long-term strength of nano-reinforced hcp metal crystals in question is believed to be attributed to the GBs pinning by the nanoparticles embedded into their matrices. The thermally activated dislocation climb mechanism is suspected to be the ratecontrolling mechanism responsible for the beneficial effect of nanoreinforced strengthening for hcp metal alloys under investigation.

F. Some deterioration of long-term strength is observed in the unrefined zirconium alloys in question upon slowing down the creep strain rates over the range from $10^{-6}$ to $10^{-9} \mathrm{~s}^{-1}$. The change of dislocation damping with temperature in the hcp $\mathrm{Zr}$ matrix containing up to $0.15 \% \mathrm{O}_{2}$ gives the first evidence for the preferential segregation of oxygen on strain-produced dislocations to form Cottrell dense atmospheres pinning dislocations with strong binding energy of about $2.0 \mathrm{eV}$. The weakening of nano-dispersion strengthening of commercially available alloys in the hcp Zr-Nb-Sn$\mathrm{nm} \mathrm{ZrO}_{2}$ system with slowing down the creep strain rates $\left(10^{-6}-10^{-}\right.$ $\left.{ }^{9} \mathrm{~S}^{-1}\right)$ is associated with the shielding effect due to a strong Cottrell locking of mobile dislocations by the large quantity of interstitial oxygen impurities which are assumed to inhibit the interaction between glide dislocations and solutes in the thermally activated range, as consistent with Cottrell-Bilby theory. It is reasonable to suppose that lowering of impurity interstitials and trace elements in raw materials in combination with nanophase strengthening which extends the uniform strain range may be considered as an effective means of impeding the shear localization in hcp crystals with sliding systems deficiency.

In the following, we assume that science-based modifying a chemical composition and aligning a structure of defect metal crystals due to the nano-reinforced strengthening minimize the strain localization effects responsible for the lower strength and degradation of micromechanical properties. In this respect, the method of nanophase strengthening takes precedence over age-hardening when overcoming the concentrated sliding with localized shear. Nanophase strengthening is most likely to extend an amount of uniform tensile strain responsible for the formation of dislocation creep resistance and the delayed effect of a premature fracturing. 
It thus appears that there may be considerable scope for further alloy development. Such an approach is believed to be a powerful starting point and considerable scope for further improvement of the newly developed alloys with minimal tendency to localized shear. The research is not only motivated by the basic science aspect but also the expectation that novel properties will lead to new technological and industrial applications. It is hoped that the basic information obtained would assist in the further development of new families of discontinuously nano-reinforced hcp magnesium and hcp zirconium alloys with the potential for technological applications at higher temperatures and stresses.

The nanophase strengthening by nano-dispersoids in association with nano-precipitation hardening should be considered as an effective means of producing a desirable combination of dislocation creep resistance, thermal stability and long-term strength of hcp crystals with deficiency of sliding systems, Both mechanisms appear well suited for their development to overcome the embrittling problems concerning planer slip and strain localization. Furthermore, chemically homogeneous alloys and their higher-speed treatment are required for the uniform bulk distributions of nanoparticles during their processing in the multicomponent alloys under consideration.

\section{Acknowledgement}

The author is indebted to Prof. A.I. Dechtyar, Prof. B.A. Movchan and Prof. M.V. Stern for their continued interest and advice throughout the course of this research. This research did not receive any specific grant from funding agencies in the public, commercial, or not-for-profit sectors. The author declares no conflict of interest.

\section{References}

1. Kassner ME (2015) Fundamentals of creep in metals and alloys. ( $3^{\text {rd }}$ edn), p. 338.

2. Abraschian R, Abraschian L (2009) Reed-hill: Physical metallurgy principles. ( $4^{\text {th }}$ edn $)$, USA, p. 750.

3. Pekguleryuz MO, Kaya AA (2003) Creep resistant magnesium alloys for powertrain applications. Advanced Engineering Materials 5(12): 866878.

4. Fleisher RL (1985) High-temperature, high-strength materials-an overview. J Metals 37: 16-20.

5. Mandal PK (2016) Study of hardening mechanisms in aluminium alloys. Int Journal of Engineering Research and Applications 6(1): 91-97.

6. Tkachenko VG (2009) Contemporary trends of the development of physics of light metals. 10(1): 103-130.

7. Jayaram J, Kaghunath BK, Rao TH (2012) Recent development and challenges in synthesis of magnesium matrix nano composites-a review. Int J of Latest Research in Science and Technology 1(2): 164-171.

8. Honeycombe RWK (1984) The plastic deformation of metals. In: Edward A (Ed.), ( $\left.2^{\text {nd }} e d n\right)$, p. 483.

9. Edgar JS (1982) The application of the fundamentals of strengthening to the design of new aluminium alloys. Strength of Metals and Alloys, pp. 1025-1044.

10. Motta AT, Couet A, Comstock RJ (2015) Corrosion of zirconium alloys used for nuclear fuel cladding. Annual Review of Materials Research 45: 311-343.
11. Hadjipanayis GC, Siegel RWV (1994) Nanophase materials: Synthesisproperties-application. Condensed Matter Physics, p. 260.

12. Gilman PS (1983) The physical metallurgy of mechanically alloyed dispersion-strengthened Al-Li-Mg and Al-Li-Cu alloys. In: Sanders TH, Starke EA (Eds.), Aluminium Lithium Alloys, pp. 485-506.

13. Tkachenko VG, Kim KH, Moon BG, Vovchok AS (2011) Design and microstructural analysis of magnesium alloys for dynamical applications. J Mater Sci 46(14): 4880-4895.

14. Tkachenko VG (2013) Physical theory of long-term strength of metallic crystals. Strength of Materials 45(5): 555-564.

15. Tkachenko VG (2019) Cluster compound formation in metal alloys crystals. Materials Today Communication 21: 100662.

16. Zhu X, Birringer R, Herr U, Gleiter H (1987) X-ray diffraction studies of the structure of nanometer-sized crystalline materials. Phys Rev 35(17): 9085-9090.

17. Ti H, Keiser JI, Landford EJ, Mittermeijer EJ, Vogels ABP (1982) Use of the voigt function in a single-line method for the analysis of X-ray diffraction line broadening. J Appl Cryst 15(3): 308-314.

18. Gjesland H, Nussbaum G, Regazzoni G, Lohne O, Baugner O (1991) Stressrelaxation and creep behaviour of some rapidly solidified magnesium alloys. Mater Sci Eng 134: 1197-1200.

19. Cottrell AH, Bilby BA (1949) Dislocation theory of yielding and strain ageing of iron. Proc Phys Soc 62(1).

20. Cottrell H (1953) Dislocations and plastic flow in crystals. Science 119(3095): 223.

21. Abramov AA, Tkachenko VG (2017) Features of the formation of cluster compounds in metal solid solutions. Ukrainian Journal of Physics 62(11): 961-969.

22. Srivatsan TS, Coyne EJ, Starke EA (1986) Microstructural characterization of two lithium-containing aluminium alloys. J Mater Sci 21: 1553-1560.

23. Martin JW, Doherty RD (1997) Stability of microstructure in metallic systems. USA.

24. Caillard D (2016) DSA in iron alloys: The shielding effect of carbon. Acta Mater 112: 273-284.

25. Ritchie IC (1982) Core diffusion, unpinning and the Snoek-Koster relaxation. Scripta Metall 16: 249-253.

26. Clark JB (1968) Age hardening in a Mg-9 wt.\% Al alloy. Acta Met 16(2): 141-152.

27. Ryum N (1968) The influence of a precipitate-free zone on the mechanical properties of an Al-Mg-Zn alloy. Acta Met 16(3): 327-332.

28. Yue F, Yuri NO, Sidney Y, Bilge Y (2013) Mapping strain rate dependence of dislocation-defect interactions by atomistic simulations. PNAS 110(44): 17756-17761.

29. Arzt E, Wilkinson DS (1986) Threshold stress for dislocation climb over hard particles: The effect of an attractive interaction. Acta Metall 34(10): 1893-1898.

30. Rosler J, Arzt E (1990) A new model-based creep equation for dispersion strengthened materials. Acta Metal Mater 38(4): 671-683.

31. Granato A, Lücke K (1956) Theory of mechanical damping due to dislocations. Journal of Applied Physics 27(6): 583-593.

32. Vasudévan K, Ludwiczak EA, Baumann SF, Howell PR, Doherty RD et al. (1986) Grain boundary fracture in Al-Li alloys. Mat Sci Techn 2(12): 1205-1209.

33. Cormick PGM (1988) Theory of flow localization due to dynamic strain aging. Acta Metall 36(12): 3061-3067. 
34. Schoeck G (1956) Moving dislocations and Solute Atoms. Phys Rev 102(6): 1458-1459.

35. Valiev RZ, Alexandrov IV, Zhu YT, Lowe TC (2011) Paradox of strength and ductility in metals processed by severe plastic deformation. pp. 5-8.
36. Conrad H (1964) Thermally activated deformation of metals. JOM 6(7): 582-588.

37. Ritchil IG, Atrens A, So CB, Sprungmann KW (1981) Dislocation relaxation in a random array of solutes. Journal of Physique $42(10)$ : 319-322.

For possible submissions Click below: 